\section{L-PEACH: A Computer-based Model to Understand How Peach Trees Grow}

\author{
Gerardo Lopez ${ }^{1,2}$, Romeo R. Favreau ${ }^{1}$, Colin Smith ${ }^{1}$, \\ and Theodore M. DeJong ${ }^{1,3}$
}

\begin{abstract}
ADDITIONAL INDEX WORDS. carbohydrate assimilation, partitioning, L-systems, physiology, Prunus persica, source-sink interactions, three-dimensional, growth simulation
\end{abstract}

SUMMARY. L-PEACH is a computer-based model that simulates the growth of peach [Prunus persica (L.) Batsch] trees. The model integrates important concepts related to carbon assimilation, distribution, and use in peach trees. It also includes modeling of the responses to horticultural practices such as tree pruning and fruit thinning. While running L-PEACH, three-dimensional (3D) depictions of simulated growing trees can be displayed on the computer screen and the user can easily interact with the model. Quantitative data generated during a simulation can be saved to a file or printed for visualization and analysis. L-PEACH is a powerful tool for understanding how peach trees function in the field environment, and it can be used as an innovative method for dissemination of knowledge related with carbohydrate assimilation and partitioning. In this study, we describe the version of L-PEACH that runs on a daily time-step (L-PEACH-d) and how users can run the model and interact with it. To demonstrate how L-PEACH-d works, different pruning and fruit thinning strategies were analyzed. Regarding pruning, model outputs showed 3D depictions of unpruned trees and pruned trees trained to a perpendicular $\mathrm{V}$ system. For the fruit thinning studies, we simulated different intensities and dates of fruit thinning in mature peach trees. Total simulated yield increased with crop load but the opposite was observed for average fruit weight. An optimal balance between simulated total yield and average fruit weight was obtained by leaving 150 fruit per tree. Simulating different dates of fruit thinning indicated that fruit weight at harvest was higher on earlier compared with later-thinned trees. The model indicates that fruit thinning should be therefore carried out early in the season to maximize fruit size. The simulation results demonstrate that L-PEACH-d can be used as an educational tool and facilitate the adoption of suitable cultural practices for efficient production.

$\mathrm{I}$ $\mathrm{n}$ peach trees, as in other plants, the energy used to create carbohydrates that support growth and development comes from solar radiation through the process of photosynthesis. Peach tree productivity is therefore dependent on the tree's photosynthetic efficiency and effectiveness in distributing and using carbohydrates. A basic knowledge of carbon assimilation and partitioning concepts at the whole-tree

This research was supported in part by the grants from the California Tree Fruit Agreement and the California Cling Peach Board to T.M. DeJong.

We thank Evelyne Costes, Yann Guédon, Przemyslaw Prusinkiewicz, Mitch Allen, Yaffa Grossman, Radek Karwowski, Pavol Federol, Lars Mündermann, Peter MacMurchy, Brendan Lane, Mik Cieślak, and Alla Seleznyova for their assistance/consultations in model development. For installation instruction details contact Gerardo Lopez at gerardo.lopez@irta.es.

${ }^{1}$ Department of Plant Sciences, University of California, 1035 Wickson Hall, One Shields Avenue, Davis, CA 95616

${ }^{2}$ Irrigation Technology, Institut de Recerca i Tecnologia Agroalimentàries, 191 Rovira Roure, Lleida 25198, Spain

${ }^{3}$ Corresponding author. E-mail: tmdejong@ucdavis.edu. level can aid in understanding how peach trees grow and facilitate the adoption of suitable cultural practices for efficient production.

Carbon assimilation and partitioning are dynamic, interrelated, complex phenomena. Canopy carbon assimilation is dependent on the physiological stage of the leaves and numerous external factors including light environment within the canopy and air temperature (DeJong and Moing, 2008). Total fruit carbohydrate demand at different stages of development also influences carbon assimilation and partitioning. For instance, leaf photosynthesis can increase when the demand of fruit for carbohydrates is high (BenMimoun et al., 1996). A major decrease in leaf photosynthesis was observed after harvest (BenMimoun et al., 1996). The overall partitioning of carbohydrates within the tree is even more complex than the assimilation process. All the tree organs require carbohydrates for growth and maintenance. But requirements for carbohydrates vary among tree organs and their stages of development. Besides the genetic potential and the stage of development of a given organ, its actual growth depends on assimilated carbon availability and interorgan competition for carbohydrates (DeJong and Moing, 2008). Much research has been done to document and understand peach organ functionality and source-sink interactions individually (DeJong and Grossman, 1995; Grossman and DeJong, 1995a, 1995b; Pavel and DeJong, 1993). However, the integration of all these concepts at the whole-tree level and over multiple years is difficult and requires a modeling approach.

Several carbon-based models have been designed to integrate carbon assimilation, organ respiration, reserve dynamics, allocation of assimilates, and growth in trees (Le Roux et al., 2001). In the case of peach, Grossman and DeJong (1994) successfully developed a mechanistic computer model, PEACH. PEACH included important concepts related to carbon assimilation and its distribution in peach trees, and it has been an important reference for subsequent research (over 125 citations by the end of 2009). However, $\mathrm{PEACH}$ did not simulate changes in architecture over time. Ignoring interactions between tree architecture and carbon allocation was the major limitation of the PEACH model (Le Roux et al., 2001). To understand how peach trees grow, it is important to understand the dynamic feedback between carbon allocation and tree architecture. This can be obtained with the construction of a functional-structural plant model (Marcelis and Heuvelink, 2007; Vos et al., 2007).

Recent advances in computer technology have introduced several

\begin{tabular}{llll}
\hline $\begin{array}{l}\text { Units } \\
\text { To convert U.S. to SI, } \\
\text { multiply by }\end{array}$ & U.S. unit & SI unit & $\begin{array}{l}\text { To convert SI to U.S., } \\
\text { multiply by }\end{array}$ \\
\hline 2.54 & inch(es) & $\mathrm{cm}$ & 0.3937 \\
0.4536 & $\mathrm{lb}$ & $\mathrm{kg}$ & 2.2046 \\
28.3495 & $\mathrm{oz}$ & $\mathrm{g}$ & 0.0353
\end{tabular}


tools that can help in the construction of functional-structural plant models. combination of 20 years of experience with carbon partitioning in peach trees and computer-based simulation. L refers to L-systems, a language used to model the growth processes of plant development (Lindenmayer, 1968; Prusinkiewicz and Lindenmayer, 1990). While running L-PEACH, 3D architectural depictions of simulated growing trees can be visualized on the computer screen in daily time-steps (Fig. 1). Other models also have included 3D architecture to simulate photosynthesis in peach trees (Génard et al., 2000) or development of apple trees [Malus $\times$ domestica (Borkh.)] in interaction with gravity (Costes et al., 2008). But L-PEACH is the first model to simulate growth and carbon sourcesink relationships within the architectural framework of a peach tree over multiple years. Moreover, L-systems allow multiple interactions with the model (Prusinkiewicz et al., 2007b). At any time during the simulation, the user can easily interact with the tree shown on the computer screen and modify some of its features to simulate pruning or fruit thinning. Simulated responses can be observed visually on the screen, in quantitative data files generated during a simulation, or both, including individual organ growth and functionality, carbohydrate assimilation, reserve storage and mobilization, and maintenance respiration. Therefore, L-PEACH is a tool to understand $\mathrm{L}-\mathrm{PEACH}$ model is the result of the

the functional carbon economy of peach trees, to show how fruit trees function in field environments, and to predict tree growth and crop yield responses.

Early reports described how LPEACH was designed (Allen et al., 2005). Further research explained how quantitative data generated during a simulation can be transferred in the form of text files to perform data analysis and display results in the form of plots (Allen et al., 2007). A later version included more explicit details for simulating shoot growth and resulted in more realistic simulations of tree architecture (Lopez et al., 2008a). Quantitative validation of the model at the whole plant and individual organ levels indicated that the model results were in general agreement with observations of real peach trees growing under optimal field conditions (Lopez et al., 2008a). Moreover, important concepts related with commercial practices, such as fruit thinning (Lopez et al., 2008b) and pruning (Smith et al., 2008; T.M. DeJong, C. Negron, R. Favreau, E. Costes, Y. Guedon, and G. Lopez, unpublished), were included in this version of the model. Continued development of the L-PEACH model is ongoing. While the model being discussed in this article (L-PEACH-d) runs on a daily time-step, a newer version (L-PEACH-h) that incorporates water as well as carbon transport and runs on an hourly time-step is currently under development. However, the hourly model runs much

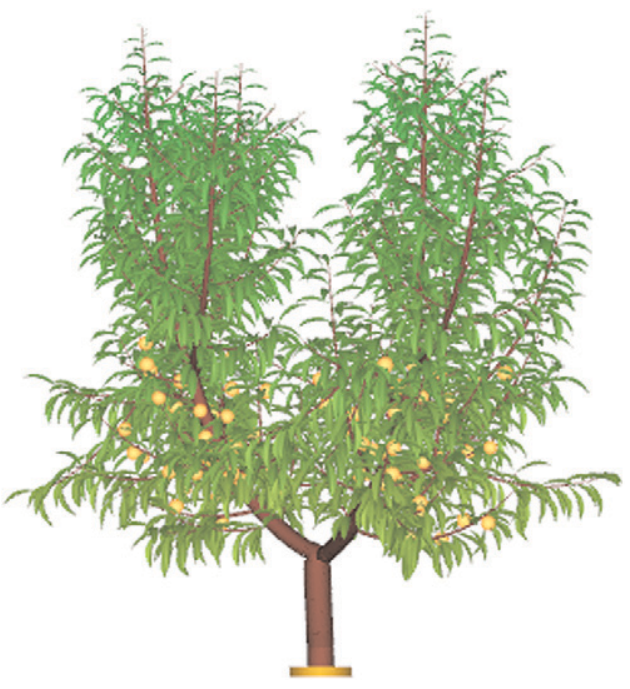

Fig. 1. L-PEACH-d output showing a three-dimensional depiction of a peach tree in its third year of growth. slower than the daily model because of a higher number of calculations. LPEACH-h will likely not be as useful for performing simulations of the effects of horticultural practices such as pruning and fruit thinning on tree growth and yield. Thus, with the confidence of having developed a useful tool for learning how peach trees grow in response to horticultural practices, the next step is to disseminate the LPEACH-d model for its use in different communities (scientific inquiry, grower demonstration, and classroom instruction). This requires the basics of how to install, run, and interact with the model. The goal of this study is to provide information that can increase the accessibility of L-PEACH-d to a broader audience and facilitate the implementation of the model as an innovative teaching method or horticultural management decision tool. Followed by a brief description of the model, this article includes details about software requirements and installation, how to perform simulations, and how users can interact with the model. Selected simulations are presented to demonstrate some applications of the model.

\section{L-PEACH description}

A conceptual schema of the LPEACH-d model is presented in Fig. 2. Environmental factors are used as inputs to the model. These include daily solar radiation and daily maximum and minimum temperatures. In California, these data can easily be obtained from California Irrigation Management Information System weather stations. Some user-defined parameters are also required to start a simulation. These provide flexibility in running simulations for different cultivars and conditions. Details of these parameters are provided in Lopez et al., (2008a), and how users can introduce these parameters is explained later.

Input data interact with four components of the model (Fig. 2):

1) Organ functionality submodels. In this component, the functionality of each organ type was programmed using rules based in previous research (Grossman and DeJong, 1994). These include concepts of growth, maintenance respiration, and carbohydrate storage and remobilization. Leaves are programmed to perform net photosynthesis and assimilate carbohydrates within the tree after computing light 
interception for each leaf as described in Lopez et al. (2008a). One important characteristic of L-PEACH-d is that all the aboveground organs (leaves, fruit, flowers, buds, and stem segments of shoots) are considered as individual organs. Their position within the tree has been programmed to resemble realistic tree depictions in the computer screen. L-PEACH-d also simulates interactions between fruit set and natural fruit abscission (Lopez et al., 2008b). The root system is treated collectively as a single module. Organ functionality of each organ is fully described in Lopez et al. (2008a).

2) Architectural model. The architectural model was implemented using L-system (Prusinkiewicz and Lindenmayer, 1990) and Markovian model concepts (Guédon et al., 2001). L-systems integrate all the organs of the tree, and the Markovian models define branching and flowering patterns as described in Lopez et al. (2008a). This approach produces realistic tree architecture simulations (Fig. 3).

3) Carbohydrate movement within the tree. L-PEACH-d includes an algorithm that simulates carbohydrate interactions between organs and its transport within the tree. An analogy between the flow of resources in a plant and the flow of current in an electric circuit was used to model carbohydrate transport within the tree (Prusinkiewicz et al., 2007a). Details of the implementation of this algorithm in L-PEACH-d have been described in Allen et al. (2005).

4) Commercial practices submodels. Fruit thinning and pruning responses have been incorporated into the model to simulate the effect of these practices on tree growth and development. Details of fruit thinning and pruning implementation are given in Lopez et al. (2008b) and Smith et al. (2008).

Rules governing these four components of the model collectively determine growth and development of the organs that make up the simulated tree. In each daily step, 3D depictions of the simulated tree can be defined graphically using the L-studio (4.0) software (Fig. 1). At the same time, text files with quantitative data for each organ are generated. For example, in the case of the leaves it is possible to analyze the patterns of intercepted light, net photosynthesis, carbohydrate assimilation, and the amount of carbohydrates used

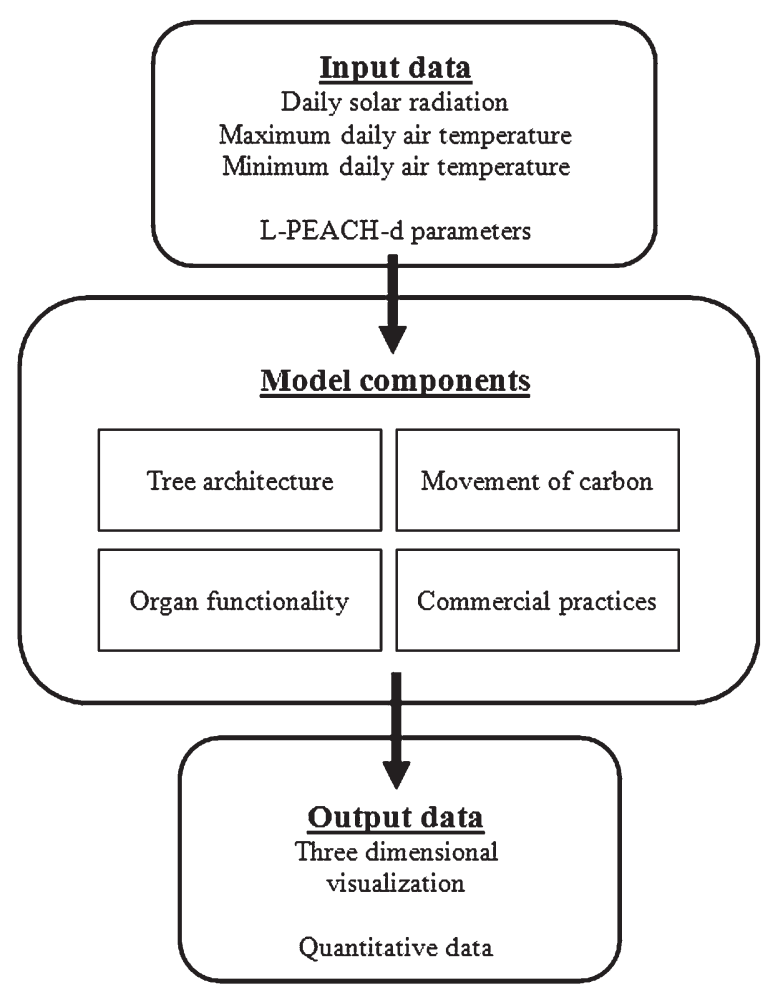

Fig. 2. Conceptual framework of the L-PEACH-d model. Actual environmental data files are used as inputs. The model contains four major components, which involve sub-models for simulating dry matter partitioning and growth responses to environmental and management inputs, and outputs can be evaluated as three-dimensional simulated trees and numerically.

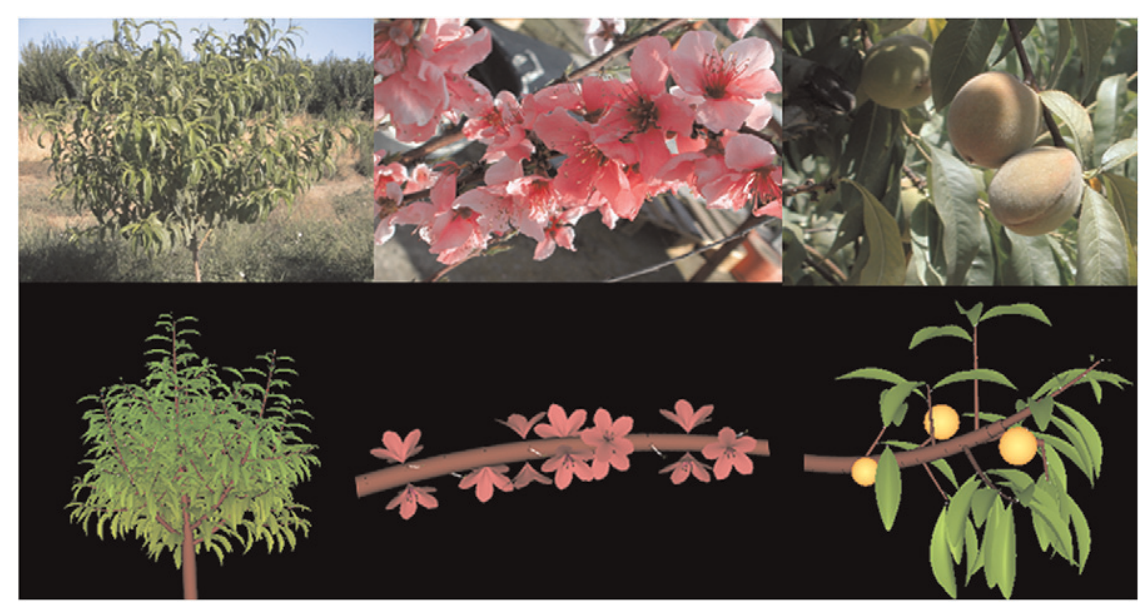

Fig. 3. Visual comparison of pictures of field-grown peach trees (above) and graphical outputs of L-PEACH-d (below).

for respiration. Moreover, quantitative outputs for the whole-tree are also generated. These may include total tree photosynthesis, carbohydrate assimilation, weight accumulation in each organ type, and the total amount of carbohydrates accumulated in storage organs. Some of these outputs have been previously presented in Allen et al. (2007) and Lopez et al. (2008a).

\section{Running L-PEACH-d}

HARDWARE AND SOFTWARE REQUIREMENTS AND INSTALLATION. L-PEACH-d does not require any specific hardware but it has some software requirements. L-PEACH-d code was written in the $\mathrm{L}+\mathrm{C}$ plant modeling language (Prusinkiewicz et al., $2007 \mathrm{~b}$ ) and implemented using the L-system-based modeling software 
L-studio (4.0) (Prusinkiewicz, 2004). To run L-PEACH-d, the user therefore needs L-studio software. L-studio may only be used with a valid license that can be obtained by contacting the department of computer science of the University of Calgary (Karwowski and Lane, 2004). L-studio runs under Windows operating systems [95, 98, Me, NT4, 2000, XP (Microsoft, Redmond, WA)] and requires a $\mathrm{C}++\mathrm{com}-$ piler capable of generating Windows Dynamic Link Libraries (DLLs). LPEACH-d was developed and tested with Microsoft Visual C++. Users can obtain L-PEACH-d program code by contacting the corresponding author of this publication. Along with the L-PEACH-d code a document that covers its installation is available. Installation instructions for suggested tools including free licensed text editors and compilers well suited to editing $\mathrm{C}++$ and $\mathrm{L}+\mathrm{C}$ code are also available. For installation instructions, details, and common installation problems, users can contact the first author of the publication.

DOING SIMUlations with LPEACH-d. L-PEACH-d includes a graphical user interface (GUI) (Fig. 4) developed in the Qt cross-platform $\mathrm{C}++$ application framework (version 4.3; Trolltech, Oslo, Norway). The GUI allows users to run L-PEACH-d without getting involved in the programming code.

At the beginning of a simulation, users can parameterize their own simulations by modifying established default parameters. These parameters include calendar dates for the phenological stages of the tree (floral budbreak, full bloom, vegetative budbreak, bud dormancy, and start and end of leaf abscission), some leaf, stem segment, fruit, and root characteristics and management practice parameters (day of budding, fruit thinning date, and harvest date). Once initial parameters are selected in the GUI, users can run L-PEACH-d by choosing "Go" from the GUI. L-studio will open two windows on the computer screen. The main window depicts the 3D growing tree and the other sub-window shows some selected quantitative data and buttons that allow user interactions with the model (Fig. 5).

In the first year of simulated growth, the tree is initiated with a small root and a stem segment that has a leaf, a vegetative terminal bud,

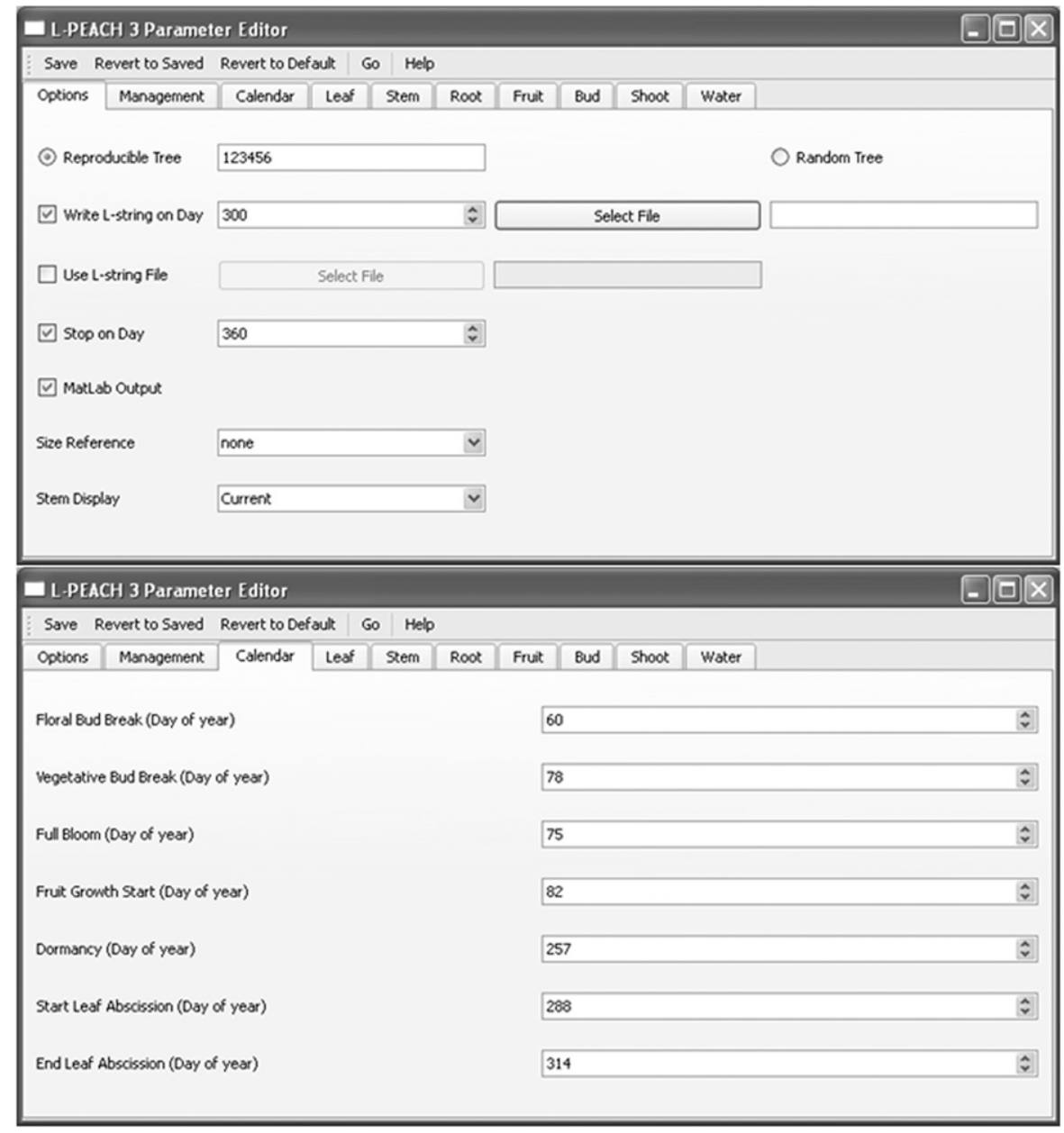

Fig. 4. The graphical user interface allows users to specify a limited number of parameters and run L-PEACH-d without getting involved in the programming code.

a vegetative axillary bud, and an axillary latent bud. This represents a young seedling tree in the nursery. By doing a click with the right button of the mouse in the computer screen, a Windows menu command appears. Users can select different options including Run, Stop, Reset, Exit, etc. If the user selects "Run," the simulation begins and tree growth and carbohydrate assimilation and partitioning is modeled based on the rules of the four components of the model summarized in Fig. 2. If the user does not interact with the model, an unpruned tree will grow indefinitely. However, budding during the first year of growth is automatically simulated without user's intervention because the goal of the modeling effort was to simulate the growth of commercial fruit trees. At the selected heading date (selected in the parameter window), the simulated young tree is automatically pruned back to the scion bud from which the tree then grows.

INTERACTING WITH L-PEACH-d. While the simulation is running in the computer window, the user can easily interact with the model. There are two interactions available by selecting Ctrl+Shift+Click with the computer keyboard and the left button of the mouse. The first one allows application of pruning and fruit thinning. To prune or thin the tree, the user can select a "Prune" button from the data sub-window (Fig. 5). This will cause the simulation to be paused and the leaves to be hidden (if they are present). Selecting branches or fruit with a left click of the mouse will make their distal end change color so that the user can see what will be removed (users can Click anywhere on any branch). If the highlighted branches or fruit are what the user wants to remove, the user clicks on a "Commit" 
button, if not, the user can select an "Undo" button and start again (Fig. $5)$. When pruning or thinning is finished, the user can select the pruning button again and the tree simulation will continue. A comparison of simulations between unpruned and pruned trees is presented in Fig. 6. The second interaction with the model allows modifications of the properties that are visualized by the stem's colors. This can be done by selecting the "Stem Display" button following mouse selection procedures described previously (results not shown). The stem display options are "bark" for a barklike color, "current" to view the direction of carbohydrate movement as the simulation runs, "shoot type" to differentiate the length categories of the shoots, "order" to display the branching order of all the shoots on the tree, and "zone," "bud type," and "num flowers" for the zone, type of bud, and number of lateral flowers, respectively. More information about the meaning of the different colors is reported in a pdf document attached to the GUI's help menu. Some examples are shown in Allen et al. (2005).

DOING EXPERIMENTS WITH LPEACH-d. A practical feature allows model outputs to be saved at any time during the simulation and then the model can be repeatedly restarted from the same point. This allows simulated management experiments to be repeated on the same tree and eliminates the need to start each simulation from the beginning. To save a simulation, the user has to activate a box in the GUI called "write L-string filename," type a name into the box and, in another box, select the day of the year in which the L-string will be saved (Fig. 4). The user can then use this previous L-string file to start a subsequent simulation. If subsequent simulations are initiated with a saved string, L-studio will open a window with the tree that was saved in the previous simulation. Users also have the opportunity to modify selected parameters if desired so that different growing conditions can be imposed on the same tree.

At the end of a simulation, multiple outputs with quantitative data are automatically generated (Table 1). These data are in the form of text files and include information for each organ and day of simulation. To facilitate analysis of data, some scripts

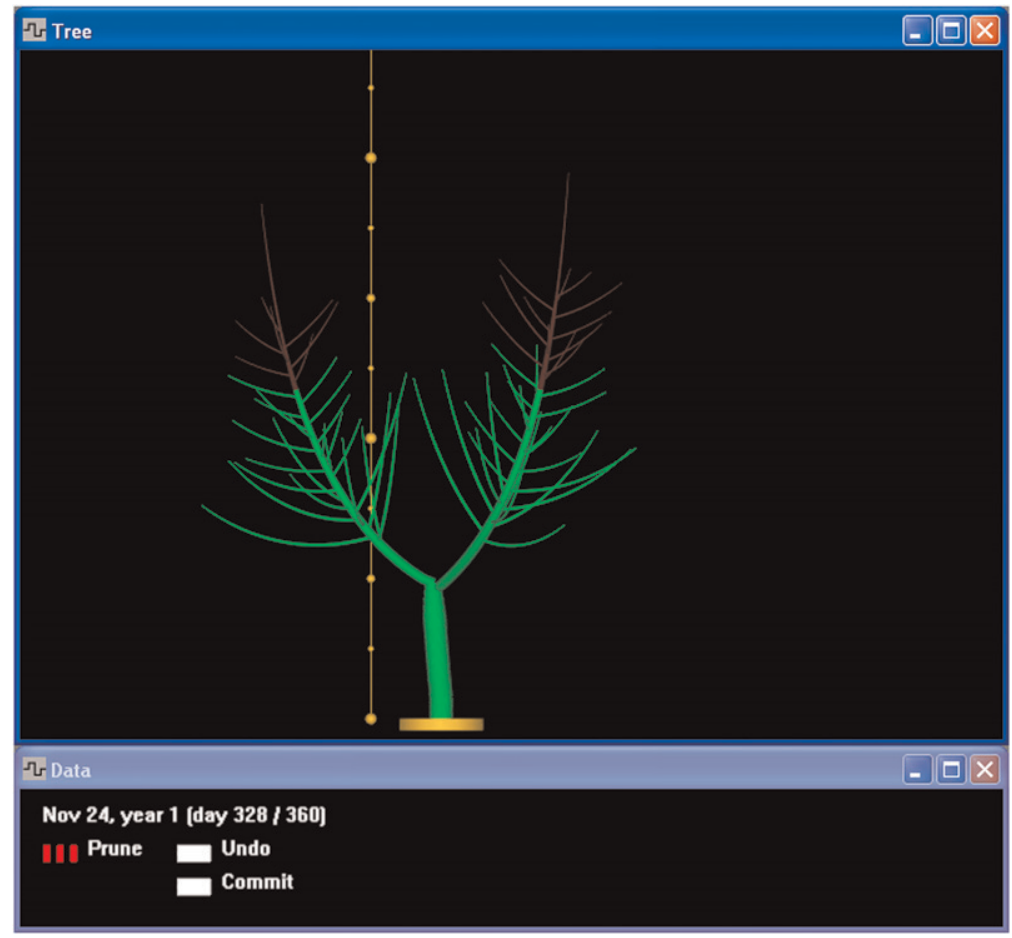

Fig. 5. Interacting with L-PEACH-d on the computer screen to make pruning cuts in winter. The "Prune" button from the data sub-window was selected. The simulation was automatically paused, and branches acquired a green color. Ends of the two main scaffolds were selected with two left clicks of the mouse. Selected branches changed to a brown color so that the user can see what will be removed. If the highlighted branches are what the user wants to remove, they should select the "Commit" button. If not, the user can select the "Undo" button and start again. When done pruning, the user can select the "Prune" button again and the simulation will continue. Tree height in centimeters is indicated by a vertical ruler. Each section of the ruler represents $25 \mathrm{~cm}(1 \mathrm{~cm}=0.3937$ inch $)$.

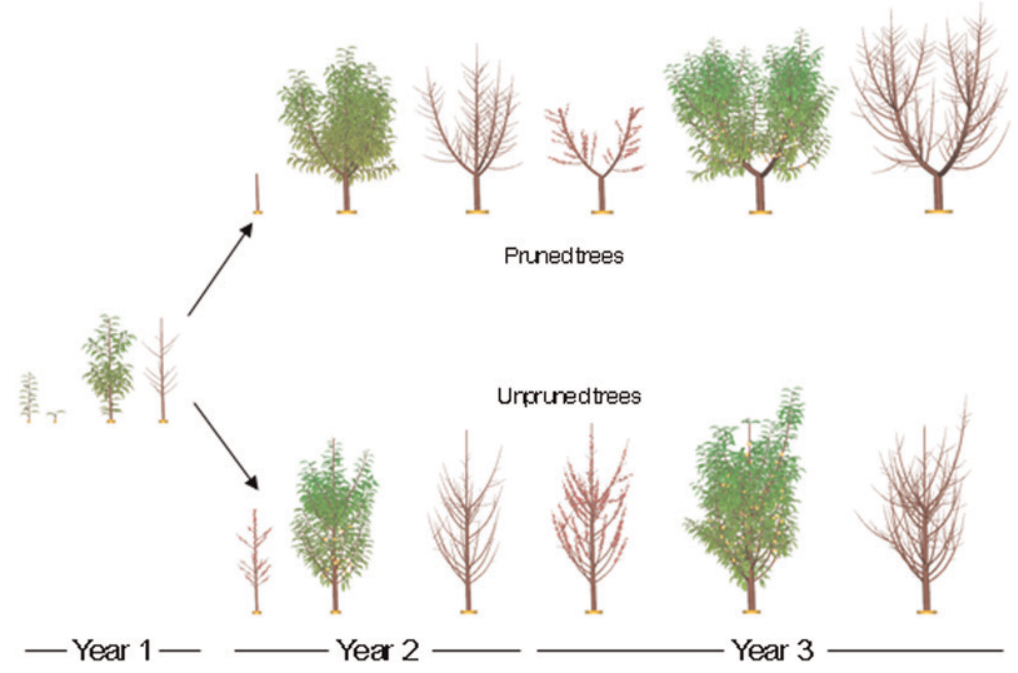

Fig. 6. Model output showing a three-dimensional depiction of a pruned peach tree and an unpruned peach tree over 3 years of growth. The pruned tree was trained to a perpendicular $\mathrm{V}$ system by means of pruning cuts at the beginning of the second and third years of growth.

have been developed using MATLAB (version 7.0, release 14; Mathworks, Natick, MA) and are available along with the code. But other data analysis software packages could be used for creation of graphs.

Example Simulations. LPEACH-d offers the opportunity to 
run simulations under different environmental conditions and analyze the effects of different pruning and fruit thinning strategies. As examples of LPEACH-d versatility, graphic depictions of simulated pruning (Fig. 6) and fruit thinning simulations were developed as follows. For the thinning studies we simulated pruning and peach tree growth until the beginning of the fourth growing season and then saved all the model outputs. Trees were pruned on the computer screen to a perpendicular V-shaped tree (DeJong et al., 1994). Then simulations were restarted multiple times from the same point using different fruit thinning strategies to simulate the effect of crop load and date of fruit thinning on peach fruit growth and productivity.

To determine the effect of crop load on fruit productivity, six fruit thinning intensities were applied 60 $\mathrm{d}$ after bloom. The total number of fruit for the six simulations was 25,50 , $100,200,250$, and 350 fruit per tree (Fig. 7). Total yield (kilograms per tree) increased with increases in crop load, but the opposite was observed for average fruit weight (grams per fruit). The pattern of the simulated interactions between crop load and fruit size was very similar to the classic, empirically derived relationships reported by Cain and Mehlenbacher (1956). Financial return to growers for their crop is generally based on size and quantity of fruit produced, with an optimal balance between the two. L-PEACH$\mathrm{d}$ simulations can help to understand the dynamics of this compromise and optimize fruit thinning intensity.

To determine the effect of the date of fruit thinning on peach productivity, the simulated tree was either not thinned or thinned to the same fruit load (leaving a fruit every $10 \mathrm{~cm}$ ) on four different dates; at bloom and 30, 60, and $90 \mathrm{~d}$ after bloom. Crop load at harvest on unthinned and thinned trees was 887 (number of fruit remained after natural fruit abscission) and 220 fruit per tree, respectively. Unthinned trees had the lowest individual mean fruit dry weight values (Fig. 8). Within thinned trees, mean individual fruit dry weight at harvest tended to be higher on earlier than on later-thinned trees (Fig. 8). The substantial benefit achieved from reducing time between bloom and fruit thinning on average fruit dry weight was

Table 1. Summary of results that can be analyzed after the completion of a simulation with the L-PEACH model.

\begin{tabular}{|c|c|}
\hline Parameter (units) & Organ category \\
\hline $\begin{array}{l}\text { Number (cardinal number ordered by } \\
\text { the time of occurrence in the tree) }\end{array}$ & Leaves, stem segments, and fruit \\
\hline $\begin{array}{l}\text { Position in the tree }[x, y \text {, and } z \\
\text { coordinates }(\mathrm{cm})]^{z}\end{array}$ & Leaves, stem segments, and fruit \\
\hline Area $(\mathrm{cm})$ & Leaves \\
\hline Length $(\mathrm{cm})$ & Shoots \\
\hline Diameter $(\mathrm{cm})$ & Shoots \\
\hline Weight $\left[\mathrm{CH}_{2} \mathrm{O}(\mathrm{g})\right]^{\mathrm{y}}$ & Leaves, stem segments, fruit, and roots \\
\hline Light interception $\left[P A R\left(\mathrm{~mol} \cdot \mathrm{d}^{-1}\right)\right]^{\mathrm{x}}$ & Leaves \\
\hline Photosynthesis $\left[\mathrm{CH}_{2} \mathrm{O}\left(\mathrm{g} \cdot \mathrm{d}^{-1}\right)\right]$ & Leaves \\
\hline $\begin{array}{l}\text { Carbohydrate mobilized out } \\
\text { from the leaves }\left(\mathrm{g} \cdot \mathrm{d}^{-1}\right)\end{array}$ & Leaves \\
\hline Flux of carbohydrates $\left(\mathrm{g} \cdot \mathrm{d}^{-1}\right)$ & egments \\
\hline $\begin{array}{l}\text { Maintenance respiration } \\
\qquad\left[\mathrm{CH}_{2} \mathrm{O}\left(\mathrm{mmol} \cdot \mathrm{d}^{-1}\right)\right]\end{array}$ & Leaves, stem segments, fruit, and roots \\
\hline Carbohydrate storage (g) & Leaves, stem segme \\
\hline Storage mobilization $\left[\mathrm{CH}_{2} \mathrm{O}(\mathrm{g})\right]$ & Leaves, stem segments, and roots \\
\hline \multicolumn{2}{|c|}{$\begin{array}{l}\text { After a simulation, L-PEACH-d generates text files for each parameter. Within the text file appears a value for each } \\
\text { day of the simulation and for every single peach leaf, stem segment, and fruit. Only one value is generated for the } \\
\text { entire root system. The integration of single values allows obtaining text files with values for the whole tree. The } \\
\text { stem segments represent the internodes within shoots and branches. } \\
{ }^{2} 1 \mathrm{~cm}=0.3937 \text { inch. } \\
{ }^{\mathrm{C}} \mathrm{CH} \mathrm{H}_{2} \mathrm{O}=\text { carbohydrates, } 1 \mathrm{~g}=0.0353 \mathrm{oz} \text {. } \\
{ }^{x} \mathrm{PAR}=\text { photosynthetically active radiation. }\end{array}$} \\
\hline
\end{tabular}

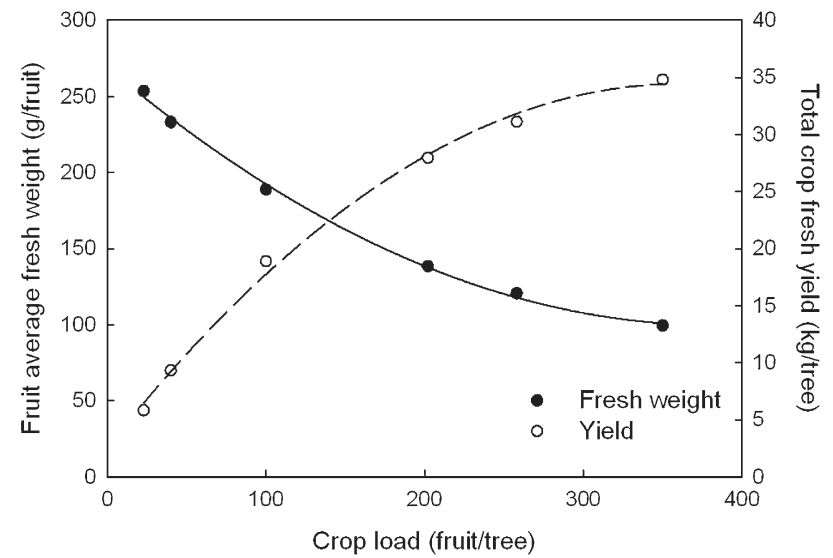

Fig. 7. Simulated relationships between peach tree crop load and fruit average fresh weight and total crop fresh yield at harvest. Results were obtained by running the model six times with different fruit thinning intensities $(1 \mathrm{~g}=\mathbf{0 . 0 3 5 3} \mathrm{oz}$, $1 \mathrm{~kg}=2.2046 \mathrm{lb})$.

similar to empirically derived responses (Grossman and DeJong, 1995b) and corresponds well to the common experience that fruit thinning should be carried out early in the season to optimize fruit size.

\section{Discussion}

This study introduces L-PEACH$\mathrm{d}$ as a new tool for understanding the functional carbon economy of peach trees and how horticultural practices such as pruning and fruit thinning can influence that economy. We explain how to obtain the L-PEACH-d model and additional software requirements and how to run simulations and interact with it. We also provide some examples of the outputs that can be obtained through its use. But to truly appreciate the potential of L-PEACH$\mathrm{d}$ model, users should interact with the model. This is the only way to appreciate all the features of the model. We are fully convinced that L-PEACH-d is a useful tool for teaching others about how peach trees grow. The possibilities are multiple and each user must take 


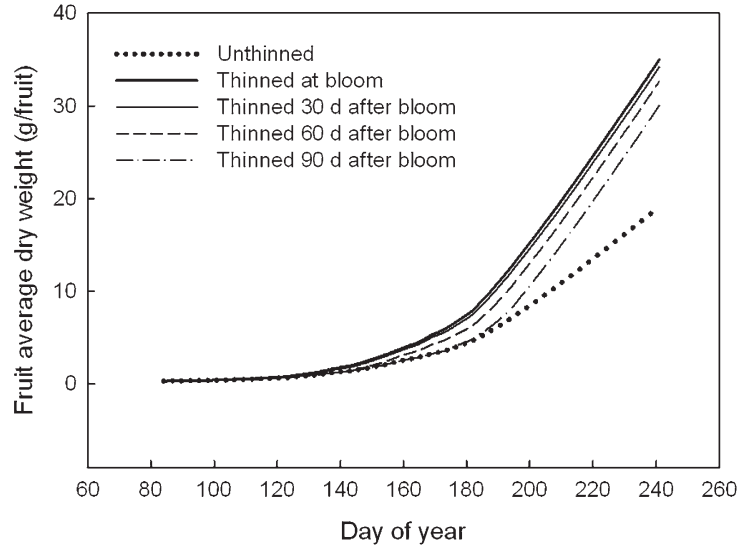

Fig. 8. Simulated seasonal patterns of mean individual fruit dry weight in response to different thinning peach fruit to the same crop load at four different times compared with not thinning the fruit. Harvest was simulated at day 240. Fruit growth simulations were obtained during the fourth growing season of a mid-late maturing peach cultivar $(1 \mathrm{~g}=0.0353 \mathrm{oz})$.

advantage of the properties of the model that are of greatest interest to them. For example, at the grower level, L-PEACH-d can be used as an educational tool for understanding responses to pruning at different times of the year, in different types of shoots, and in different positions within a given shoot or branch. Although there are many research reports that describe results of various pruning experiments, the best way to understand the complex interactions among pruning, tree growth responses, tree carbon economy, and subsequent yield responses is to be able to do pruning and then observe responses to it over short time periods. The problem is that in reality the pruning responses are not immediate and it is necessary to wait months or even years to observe the final result of the pruning cuts. By using L-PEACH$\mathrm{d}$, users can see the responses to pruning cuts immediately on the computer screen and also observe the responses to erroneous pruning cuts, which must be avoided in the field. At the university level, there are also many basic mechanisms related with carbon assimilation and partitioning that are difficult to understand by studying the existing literature. Knowledge often is based on empirical studies, and in reality many years are required to observe variable situations. With L-PEACH-d, users can perform multiple experiments in a short period of time, changing many aspects, both physiological and environmental. For example, users can observe responses to variable environmental conditions such as solar radiation or ambient temperature. In the orchard, many years (more than 10 years) may be needed to observe a broad range of environmental conditions and their effect on peach tree growth (Lopez et al., 2007; Lopez and DeJong, 2007). L-PEACH-d also allows the imposition of extreme situations that are difficult to apply in field experiments, allowing a greater understanding of tree functionality. Furthermore, because the L-PEACH-d model is based on developmental and physiological principles, it can provide understanding of the processes involved in the responses.

L-PEACH-d is not only an educational tool, but it is also a research tool. The development of L-PEACH$\mathrm{d}$ has required the inclusion of numerous concepts related to carbon assimilation and partitioning. Some of these concepts were obtained from previous literature. But other concepts required during model development were not well understood. This required reevaluation of existing concepts and the formulation of new hypotheses and design of field experiments (T.M. DeJong, Y. Grossman, G. Lopez, and R. Favreau, unpublished). New experiments derived from hypotheses generated in the development and use of L-PEACH-d are currently being performed. These include studies on peach architecture with trees growing on different rootstocks (T.M. DeJong, C. Negron, R. Favreau, E. Costes, Y. Guedon, and G. Lopez, unpublished), leaf and stem growth functionality (Auzmendi et al., 2010), modeling phloem functionality (D. Da Silva and T.M. DeJong, unpublished), and effects of severe water stress on daily peach carbohydrate assimilation (G. Lopez and T.M. DeJong, unpublished). Also, the use of L-PEACH-d by researchers working on other species has revealed that some mechanisms are well known for peach but not for other species. LPEACH-d has provided a framework for beginning the development of a 3D simulation model for almond [Prunus dulcis (Mill.) D.A. Webb], and similar research is ongoing for apple. We believe that L-PEACH-d is a useful tool for communicating and demonstrating many complexities involved in determining tree growth and yield outcomes under multiple environmental and management conditions. Numerous practical outcomes, such as better understanding of responses to fruit thinning, pruning, rootstocks, water stress, and spring and summer temperatures, have already been derived from this long-term modeling project. With this publication we are attempting to make this tool available for broader use by horticulturists interested in using it.

\section{Literature cited}

Allen, M.T., P. Prusinkiewicz, and T.M. DeJong. 2005. Using L-systems for modeling source-sink interactions, architecture and physiology of growing trees: The L-PEACH model. New Phytol. 166: 869-880.

Allen, M.T., P. Prusinkiewicz, R.R. Favreau, and T.M. DeJong. 2007. L-Peach, an Lsystem-based model for simulating architecture, carbohydrate source-sink interactions and physiological responses of growing trees, p. 139-150. In: J. Vos, L.F.M. de Visser, P.C. Struick, and J.B. Evers (eds.). Functional-structural plant modeling in crop production. Springer-Verlag, Dordrecht, The Netherlands.

Auzmendi, I., D. Da Silva, R. Favreau, and T.M. DeJong. 2010. Integration of leaf and internode growth functions in L-PEACH. In: DeJong T. and D. Da Silva (eds.). Proc. 6th International Workshop on Functional-Structural Plant Models. UC Davis Special Pub., Davis, CA.

BenMimoun, M., J.J. Longuenesse, and M. Genard. 1996. Pmax as related to leaf: Fruit ratio and fruit assimilate demand in peach. J. Hort. Sci. 71:767-775.

Cain, J.C. and R.J. Mehlenbacher. 1956. Effects of nitrogen and pruning on trunk growth in peaches. Proc. Amer. Soc. Hort. Sci. 67:139-143. 
Costes, E., C. Smith, M. Renton, Y. Guédon, P. Prusinkiewicz, and C. Godin. 2008. MAppleT: Simulation of apple tree development using mixed stochastic and biomechanical models. Funct. Plant Biol. 35:936-950.

DeJong, T.M. and Y.L. Grossman. 1995. Quantifying sink and source limitations on dry matter partitioning to fruit growth in peach trees. Physiol. Plant. 95:437-443.

DeJong, T.M., R.D. Kevin, J.F. Doyle, and R.S. Johnson. 1994. The Kearney Agricultural Center perpendicular "V" (KAC-V) orchard system for peaches and nectarine. HortTechnology 4:362-367.

DeJong, T.M. and A. Moing. 2008. Carbon assimilation, partitioning and budget modelling, p. 244-263. In: D.R. Layne and D. Bassi (eds.). The peach: Botany, production and uses. CAB International, Wallingford, UK.

Génard, M., F. Baret, and D. Simon. 2000. A 3D peach canopy model used to evaluate the effect of tree architecture and density on photosynthesis at a range of scales. Ecol. Modell. 128:197-209.

Grossman, Y.L. and T.M. DeJong. 1994. PEACH: A simulation model of reproductive and vegetative growth in peach trees. Tree Physiol. 14:329-345.

Grossman, Y.L. and T.M. DeJong. 1995a. Maximum fruit growth potential and seasonal patterns of resource dynamics during peach growth. Ann. Bot. (Lond.) 75:553-560.

Grossman, Y.L. and T.M. DeJong. 1995b. Maximum fruit growth potential following resource limitation during peach growth. Ann. Bot. (Lond.) 75:561-567.

Guédon, Y., D. Barthelemy, Y. Caraglio, and E. Costes. 2001. Pattern analysis in branching and axillary flowering sequences. J. Theor. Biol. 212:481-520.
Karwowski, R. and B. Lane. 2004. L-studio 4.0 user's guide. 28 Oct. 2010 . <http:// algorithmicbotany.org/lstudio/>.

Le Roux, X., A. Lacointe, A. EscobarGutierrez, and S. Le Dizes. 2001. Carbon-based models of individual tree growth: A critical appraisal. Ann. For. Sci. 58:469-506.

Lindenmayer, A. 1968. Mathematical models of cellular interaction in development: Part I and II. J. Theor. Biol. 18: 280-315.

Lopez, G. and T.M. DeJong. 2007. Spring temperatures have a major effect on early stages of peach fruit growth. J. Hort. Sci. Biotechnol. 82:507-512.

Lopez, G., R.S. Johnson, and T.M. DeJong. 2007. High spring temperatures decrease peach fruit size. Calif. Agr. 61: 31-34.

Lopez, G., R.R. Favreau, C. Smith, E. Costes, P. Prusinkiewicz, and T.M. DeJong. 2008a. Integrating simulation of architectural development and source-sink behaviour of peach trees by incorporating Markov chains and physiological organ function sub-models into L-PEACH. Funct. Plant Biol. 35:761771.

Lopez, G., C. Smith, R.R. Favreau, and T.M. DeJong. 2008b. Using L-PEACH for dynamic simulation of source-sink behavior of peach trees: Effects of date of thinning on fruit growth. Acta Hort. 803:209-216.

Marcelis, L.F.M. and E. Heuvelink. 2007. Concepts of modelling carbon allocation, p. 103-111. In: J. Vos, L.F.M. de Visser, P.C. Struick, and J.B. Evers (eds.). Functional-structural plant modeling in crop production. Springer-Verlag, Dordrecht, The Netherlands.
Pavel, E.W. and T.M. DeJong. 1993. Source-limited and sink-limited growth periods of developing peach fruits indicated by relative growth rate analysis. J. Amer. Soc. Hort. Sci. 118:820-824.

Prusinkiewicz, P. 2004. Art and science for life: Designing and growing virtual plants with L-systems. Acta Hort. 630: 15-28.

Prusinkiewicz, P. and A. Lindenmayer. 1990. The algorithmic beauty of plants. Springer-Verlag, New York.

Prusinkiewicz, P., M. Allen, A. EscobarGutiérrez, and T.M. DeJong. 2007a. Numerical methods for transport-resistance source-sink allocations models, p. 123137. In: J. Vos, L.F.M. de Visser, P.C. Struick, and J.B. Evers (eds.). Functionalstructural plant modeling in crop production. Springer-Verlag, Dordrecht, The Netherlands.

Prusinkiewicz, P., R. Karwowski, and B. Lane. 2007b. The $\mathrm{L}+\mathrm{C}$ plant-modelling language, p. 27-42. In: J. Vos, L.F.M. de Visser, P.C. Struick, and J.B. Evers (eds.). Functional-structural plant modeling in crop production. Springer-Verlag, Dordrecht, The Netherlands.

Smith, C., E. Costes, R.R. Favreau, G. Lopez, and T.M. DeJong. 2008. Improving the architecture of simulated trees in L-PEACH by Integrating Markov chains and pruning. Acta Hort. 803:201-208.

Vos, J., L.F.M. Marcelis, and J.B. Evers. 2007. Functional-structural plant modeling in crop production, p. 1-12. In: J. Vos, L.F.M. de Visser, P.C. Struick, and J.B. Evers (eds.). Functional-structural plant modeling in crop production. Springer-Verlag, Dordrecht, The Netherlands. 